Canadian

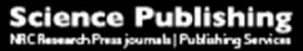

Botany

Botanique

\title{
Differences in herbivore damage to Arctium minus in open and forest habitats in its non-native range
}

\begin{tabular}{|r|l|}
\hline Journal: & Botany \\
\hline Manuscript ID & cjb-2017-0055.R1 \\
\hline Manuscript Type: & Note \\
\hline Date Submitted by the Author: & 23-May-2017 \\
\hline $\begin{array}{r}\text { Complete List of Authors: } \\
\begin{array}{r}\text { Is the invited manuscript for } \\
\text { consideration in a Special } \\
\text { Issue? : }\end{array}\end{array}$ & $\begin{array}{l}\text { Lee, Yoonsoo; University of Toronto - Mississauga, Biology } \\
\text { Kotanen, Peter; University of Toronto - Mississauga, Biology }\end{array}$ \\
\hline $\begin{array}{r}\text { Keyword: } \\
\text { invasions }\end{array}$ & $\begin{array}{l}<\text { i>Arctium minus</i>, burdock, enemy release, herbivory, biological } \\
\text { inval }\end{array}$ \\
\hline
\end{tabular}




\section{Differences in herbivore damage to Arctium minus in open and forest habitats in its non-native range}

Yoonsoo Lee and Peter M. Kotanen ${ }^{1}$

Department of Ecology and Evolutionary Biology

University of Toronto Mississauga

3359 Mississauga Road North

Mississauga, ON, L5L 1C6 CANADA

3432 words

$15 \mathrm{pp}$

${ }^{1}$ Author for correspondence

e-mail: peter.kotanen@utoronto.ca

tel: 905-828-5365; fax: 905-828-3792 


\begin{abstract}
Exotic plants do not always escape enemies in new areas; instead, they may be damaged by coinvading non-native enemies or by enemies recruited from native species. However, even when such enemies exist in an invader's new range, escape may still be possible if particular habitats offer lowdamage refuges. In this study, herbivory on the non-native common burdock (Arctium minus) were compared between open and understory habitats, with high and low sunlight exposure respectively, on five sites in Ontario, Canada. Open-habitat populations showed relatively reduced herbivore damage; this may be due to herbivores occurring less abundantly in open habitats or burdock expressing greater defences in open sites. These results emphasize that enemy release is not an absolute effect, but can depend on an individual's habitat. As well, they suggest herbivory potentially may help to confine burdock primarily to open habitats.
\end{abstract}

Key words: Arctium minus; burdock; enemy release; herbivory; biological invasions 


\section{Introduction}

Non-native plants often may benefit from reduced herbivore damage compared with competing natives, as proposed by the Enemy Release Hypothesis. This hypothesis suggests that as invading plants colonize new areas, they lose their specialized natural enemies so that they experience less herbivory, resulting in improved performance (Elton 1958; Keane and Crawley 2002; Torchin and Mitchell 2004; Liu and Stiling 2006). For example, Genton et al. (2005) showed that the North American native ragweed (Ambrosia artemisiifolia L.) experiences significantly less herbivore damage in France than in its native region. Similarly, a study showed that Norway maple (Acer platanoides L.) has significantly less leaf herbivory and fungal damage in North America compared to its native European habitats (Adams et al. 2009).

Despite such examples, enemy release is far from guaranteed. Invasive plants commonly are attacked by non-native enemies accidentally or deliberately co-introduced from their original areas. As well, these plants may be colonized by both invaded-range generalists and specialist enemies of native species that shift to these new hosts. As a result, exotics can suffer significant levels of herbivore damage, potentially impeding their success (Levine et al. 2004). However, herbivory is not a constant: it can vary substantially within the ranges of both native and exotic plants. For instance, on a geographic scale, plants often may escape enemies in marginal populations (e.g., Alexander et al. 2007; Woods et al. 2012; Nunes et al. 2016). On a more local scale, abiotic factors can result in reduced herbivory in particular habitats. First, plants that are in a more favourable environment may have the capacity to invest more in defences. For example, a plant in a sunnier site may be better able to deploy carbon-based defences against herbivores (Bryant et al. 1983). In a study of Liriodendron tulipifera L. and Cornus florida L., individuals had greater phenolic contents in sunny areas, which led to reduced herbivory on Cornus (Dudt and Shure 1994). Abiotic factors also can directly influence herbivores. Louda and Rodman (1996) provided evidence that Cardamine cordifolia Gray is restricted to shady 
habitats at least in part by greater insect herbivore abundance in sunny sites. Finally, plants may be excluded from unfavourable habitats by herbivores if they are unable to compensate adequately for damage there. DeWalt et al. (2004) found that insecticide improved survival of the invasive shrub Clidemia hirta (L.) Don in its native Costa Rica more in understory than open habitats, which they attributed to the shrub's reduced ability to tolerate damage in shady sites. Salgado-Luarte and Gianoli (2010) presented evidence that the sun-loving tree Embothrium coccineum Forst. \& Forst. similarly is excluded from understory sites because of reduced compensatory ability. Such habitat-related variation in herbivore damage can create local refuges even for those invaders that otherwise fail to escape significant enemies. In one of the classic instances of biological control, the invasive Hypericum perforatum L. in California was excluded from sunny areas by introduced beetles, but still could persist in shady areas that the beetles avoided (Huffaker and Kennett 1959).

We investigated habitat-related variation in escape from herbivores by measuring herbivore damage to the non-native species common burdock (Arctium minus (Hill) Bernh.) in open habitats and forest understories in Southern Ontario, Canada. This invader experiences high levels of foliar and capitular damage in southern Ontario, but northern populations of this plant escape most of this damage (Kambo and Kotanen 2014), likely because of reduced herbivore populations (Lee and Kotanen 2015). Evidence from its native range suggests there may be habitat-dependent escape as well. In the United Kingdom pre-dispersal predation by tephritid flies was reduced in open habitats compared to shaded sites (Straw 1991). We investigated whether herbivore damage to burdock (including both seed predation and folivory) shows similar habitat-dependent patterns in its introduced range, in the presence of both introduced specialists from Europe and new enemies from North America.

\section{Methods}

Study Species

Common burdock is an invasive Eurasian biennial now found from the southern US to every 
province of Canada (Gross et al. 1980). In Ontario, A. minus is attacked by both generalist and specialist herbivores (Gross et al. 1980; Kambo and Kotanen 2014). Herbivores include native agromyzid miner herbivores such as Liriomyza arctii Spencer (serpentine miner) and Calcomyza flavinotum (Frick) (blotch miner), many chewing folivores such as native grasshoppers (Melanoplus keeleri Thomas), exotic snails (Cepaea nemoralis (L.)), and lepidoptera including the native crambid, Herpetogramma pertextalis (Lederer), and sucking herbivores such as introduced froghoppers (Philaenus spumarius (L.)). Finally, pre-dispersal seed predators including the introduced gelechiid burdock seedhead moth (Metzneria lappella (L.)) and tephritid flies lay eggs in the capitula, where their larvae consume the seeds. According to Gross et al. (1980) Metzneria is the only Arctium specialist established in North America. Liriomyza arctii is poorly known, but was described on Arctium in North America, and presumably uses native hosts as well. The other herbivores we observed all use other hosts as well as Arctium.

\section{Study Sites}

We sampled common burdock from five mixed forest sites in Southern Ontario: Palgrave Conservation Area $\left(43.57^{\circ} \mathrm{N}, 79.51^{\circ} \mathrm{W}\right)$, the Koffler Scientific Reserve $(\mathrm{KSR})\left(44.03^{\circ} \mathrm{N}, 79.55^{\circ} \mathrm{W}\right)$, Erindale Park $\left(43.32^{\circ} \mathrm{N}, 79.39^{\circ} \mathrm{W}\right)$, Pomona Park $\left(43.48^{\circ} \mathrm{N}, 79.24^{\circ} \mathrm{W}\right)$, and Northwalk Conservation Area $\left(44.02^{\circ} \mathrm{N}, 79.06^{\circ} \mathrm{W}\right)$. These sites were dominated by maple (Acer saccharum Marshall), oak (Quercus rubra L.), and beech (Fagus grandifolia Ehrh.) trees, interrupted by disturbances such as fields and roads. At each site, we sampled five burdock populations in open habitats (including fields, forest edges, and gaps) and five in understory habitats ( 5 sites $\mathrm{x} 2$ habitats per site $\mathrm{x} 5$ populations per habitat $\mathrm{x} 10$ plants per population $=500$ plants total). To distinguish open from understory sites, we measured the transmission coefficient for diffuse light penetration for each population using a Plant Canopy Digital Imager (CID Bio-Science). The population was considered an understory site if it had a coefficient lower than 0.25 . 


\section{Data Collection and Analysis}

We measured the percentage area of leaf damage for a basal leaf, the fifth, and the tenth leaf above the basal leaf for each individual plant ( $n=30$ leaves per population) from 28 August- 2 September 2012. To calibrate measurements, we used leaf models with $1 \%, 2 \%$, and 5\% area removed. We averaged the damage values for each plant before analysis. Between 18-26 October 2012 we also counted the number of moth larvae per seedhead and then recorded the proportion of seeds damaged for one randomly-selected capitulum per plant. Not all plants were reproductive, so sample sizes were smaller than for leaf measures.

We tested for evidence of habitat effects by Analysis of Variance using an REML approach. We treated "Habitat" (understory vs. open) and "Site" as crossed fixed factors, while we included "Population" as a random blocking factor nested within the Site x Population interaction. Since proportions were continuous rather than binary variables and/or included numerous zeroes, we conventionally arcsine-transformed all proportions before analysis rather than treating them as binary or logit-transformed. We performed all analyses using JMP 12 (SAS Institute Inc.).

\section{Results}

The percentage of leaf area damaged by herbivores was greater in forest understory habitats than open habitats (overall means: $6.0 \%$ vs. $4.4 \% ; p=0.0093$; Table 1, Fig. 1A). There also were significant differences among sites $(p=0.0193)$, but the site $\mathrm{x}$ habitat interaction was not significant $(p>0.05)$. Individuals in understory habitats had on average a greater number of moth larvae in each capitulum than plants in open areas (overall means: 1.3 vs. $0.8 ; p=0.0089$; Table 1, Fig. 1B) and a significantly greater proportion of seeds damaged (overall means: $33.8 \%$ vs. 20.5\%; $p=0.0315$; Table 1, Fig. 1C). There also were significant differences among sites, but no Habitat x Site interactions.

\section{Discussion}

Our results suggest that herbivore damage to both leaves and seeds of Arctium minus is habitat- 
dependent. Even though Arctium can experience high levels of damage in its invaded range (Kambo and Kotanen 2014), local refuges from much of this damage still exist, as also can be the case for native species (e.g., Louda and Rodman 1996, DeWalt et al. 2004). This result has implications for studies of the Enemy Release Hypothesis of plant invasions. Enemy release may appear to apply in some habitats but not others, even if an invader has not escaped its enemies in a new region.

Consequently, escape during invasion cannot truly be demonstrated unless a plant is compared in similar habitats in both its native and invaded regions. Latitudinal variation in damage and performance (e.g., Kambo and Kotanen 2014) likewise can confound cross-continental studies unless properly controlled (Colautti et al. 2009).

Damage on leaves of Arctium minus was lower in open habitats than understory habitats. Mean damage levels ( 2\%-8\%) were low compared to values reported by Kambo and Kotanen (2014) (5\%$45 \%$ for comparable southern populations, dropping further north), but this likely reflects differences in sampling methodology. Kambo and Kotanen (2014) used a transparent grid to quantify damage, and sampled only basal leaves, which often have higher levels of damage. In contrast, our study used calibrated visual estimates and also sampled cauline leaves. Considering only the basal leaves in our dataset does lead to higher damage estimates (up to $20 \%$ ), but still does not eliminate this discrepancy (overall mean 5\% damage, with one population as low as $0.15 \%$ ). As well, the summer of 2012 was exceptionally hot and dry (Environment Canada 2012) leading to premature wilting of leaves (Lee and Kotanen 2015), which may have inhibited insect damage. The damage levels reported here are much closer to those in the contemporaneous common garden experiment of Lee and Kotanen (2015) $(\sim 1 \%$ $5 \%$ for 2012 data), which similarly sampled cauline leaves. Since levels of folivore damage were very low, the effect of this damage on fitness is questionable. However, some studies have indicated even minor damage may have significant effects (Marquis 1984; Schoonhoven et al. 2005), particularly in understory habitats where low light intensity already restricts photosynthesis. 
Seed damage is especially important because it directly influences the fitness of this biennial species. Plants in understory habitats had a significantly greater number of larvae of the specialist moth Metzneria in their capitula (Fig. 1B). These figures ( 0.3-2.1 larvae/capitulum) are somewhat higher than those reported in Lee and Kotanen 2015 ( $\sim 0.5-0.8$ larvae/capitulum), potentially reflecting slow colonization by herbivores of common garden plants in that study. Kambo and Kotanen (2014) did not report the number of larvae per capitulum, but the fraction of seeds damaged in southern populations ( $40 \%-90 \%$, dropping further north) was higher than found in this study (17\%-49\%, excluding a $5 \%$ outlier), possibly reflecting interannual variation; another study in southern Ontario (Hawthorn and Hayne 1978) reported intermediate levels of seed loss (28\%-71\%). Straw (1991) also found that understory plants in the UK had greater losses of seeds than plants in openings, even though these were attributable to a different family of insects (Tephritidae). He suggested that this may be due to differences in physical and chemical defences of plants in the understory and open populations, and also speculated that shaded areas may provide a better food supply and microclimate for adult insects. Whatever the explanation, this result suggests that similar constraints may operate on Arctium herbivores in both native and invaded regions.

Arctium has been accompanied to North America by at least some of its herbivores, perhaps explaining why the same pattern of damage (albeit due in part to different enemies) occurs in both invaded and native areas. More generally, Van Valen (1973) argued that herbivores prefer shaded plants because they allow herbivores to hide from predators. Thus, herbivores in shaded areas may benefit by avoiding mortality, spending less energy on behaviour or traits to avoid predators, and using less time escaping from predators and more time on feeding. Finally, herbivores may prefer the physical environment of shaded areas, for instance in order to avoid heat during summer (Maiorana 1981). This might have been especially true during the very hot summer of 2012. In addition to representing safer sites for herbivores, it also may be that open-habitat burdock plants were better 
defended or less nutritious than understory ones. In particular, drought might have caused the open-area burdock to be more stressed; as a result, burdock in open areas might have had reduced nitrogen and water content, less favourable for herbivores (Behmer 2009). Many studies of the effects of drought on plant-herbivore interaction show herbivores that feed on plants in dry environments have reduced performance, including growth and survival, due to reduced leaf nitrogen, soluble protein content, and relative water content (e.g., English-Loeb et al. 1997; Walter et al. 2012).

A corollary of the Enemy Release Hypothesis is that if invaders such as burdock fail to escape their natural enemies, they should lose the advantage they otherwise might gain over native species. The natural enemies encountered by non-native plants have the potential to reduce their competitive performance (Levine et al. 2004). Consequently, differences in herbivore damage among habitats potentially could affect an invader's habitat associations. For instance, many invasive species are disturbance-dependent or perform better in disturbed, low biomass, open areas (Hobbs and Huenneke 1992; Blumenthal 2006) than in undisturbed sites with higher plant biomass and diversity. This could be indirectly due to differences in herbivory between areas, if herbivore abundance and diversity were reduced in disturbed sites. Burdock's association with disturbed or open sites (Gross et al. 1980) may reflect lower levels of herbivory in these areas, as well as access to light and resources.

\section{Acknowledgements}

This work was supported by an NSERC Discovery Grant to PMK. We would like to thank two anonymous reviewers for their helpful comments. 


\section{References}

Alexander, H.M., Price, S., Houser, R., Finch, D., and Tourtellot, M. 2007. Is there reduction in disease and pre-dispersal seed predation at the border of a host plant's range? Field and herbarium studies of Carex blanda. J. Ecol. 95: 446-457.

Adams, J.M., Fang, W., Callaway, R.M., Cipollini, D., Newell, E., and Transatlantic Acer platanoides Invasion Network (TRAIN). 2009. A cross-continental test of the Enemy Release Hypothesis: leaf herbivory on Acer platanoides (L.) is three times lower in North America than in its native Europe. Biol. Invasions, 11: 1005-1016.

Behmer, S.T. 2009. Insect herbivore nutrient regulation. Annu. Rev. Entomol. 54: 165-187.

Blumenthal, D.M. 2006. Interactions between resource availability and enemy release in plant invasion. Ecol. Lett. 9: 887-895.

Bryant, J.P., Chapin, F.S.III, and Klein, D.R. 1983. Carbon/nutrient balance of boreal plants in relation to vertebrate herbivory. Oikos, 40: 357-368.

Colautti, R.I., Maron, J.L., and Barrett, S.C.H. 2009. Common garden comparisons of native and introduced plant populations: latitudinal clines can obscure evolutionary inferences. Evol. Appl. 2: 187-199.

DeWalt, S.J., Denslow, J.S., and Ickes, K. 2004. Natural-enemy release facilitates habitat expansion of the invasive tropical shrub Clidemia hirta. Ecology, 85: 471-483.

Dudt, J.F., and Shure, D.J. 1994. The influence of light and nutrients of foliar phenolics and insect herbivory. Ecology, 75: 86-98.

Elton, C.S. 1958. The ecology of invasions by animals and plants. Methuen, London.

English-Loeb, G., Stout, M.J., and Duffey S.S. 1997. Drought stress in tomatoes: changes in plant chemistry and potential nonlinear consequences for insect herbivores. Oikos, 79: 456-468.

Environment Canada. 2012. Canadian weather [online]. Available from 
http://www.weatheroffice.gc.ca/canada_e.html [accessed 21 March 2017].

Genton, B.J., Kotanen, P.M., Cheptou, P.O., Adolphe, C., and Shykoff, J.A. 2005. Enemy release but no evolutionary loss of defence in a plant invasion: an inter-continental reciprocal transplant experiment. Oecologia (Berlin), 146: 404-414.

Gross, R.S., Werner, P.A., and Hawthorn, W.R. 1980. The biology of Canadian weeds. 38. Arctium minus (Hill) Bernh. and A. lappa L. Can. J. Plant Sci. 60: 621-634.

Hawthorn, W.R., and Hayne, P.D. 1978. Seed production and predispersal seed predation in the biennial composite species, Arctium minus (Hill) Bernh. and A. lappa L. Oecologia, 34: 283-295.

Hobbs, R.J., and Huenneke, L.F. 1992. Disturbance, diversity, and invasion - implications for conservation. Conserv. Biol. 6: 324-337.

Huffaker, C.B., and Kennett, C.E. 1959. A ten-year study of vegetational changes associated with biological control of Klamath weed. J. Range Manage. 12: 69-82.

Kambo, D., and Kotanen, P.M. 2014. Latitudinal trends in herbivory and performance of an invasive species, common burdock (Arctium minus). Biol. Invasions, 16: 101-112.

Keane, R.M., Crawley, M.J. 2002. Exotic plant invasions and the enemy release hypothesis. Trends Ecol. Evol. 17: 164-170.

Lee, Y., and Kotanen, P.M. 2015. Differences in herbivore damage and performance among Arctium minus (burdock) genotypes sampled from a geographic gradient: a common garden experiment. Biol. Invasions, 17: 397-408.

Levine, J.M., Adler, P.B., and Yelenik, S.G. 2004. A meta-analysis of biotic resistance to exotic plant invasions. Ecol. Lett. 7: 975-989.

Liu, H., and Stiling, P. 2006. Testing the enemy release hypothesis: a review and meta-analysis. Biol. Invasions, 8: 1535-1545

Louda, S.M., and Rodman, J.E. 1996. Insect herbivory as a major factor in the shade distribution of a 
native crucifer (Cardamine cordifolia A. Gray, bittercress). J. Ecol. 84: 229-237.

Maiorana, V. 1981. Herbivory in sun and shade. Biol. J. Linn. Soc. 15: 151-156.

Marquis, R.J. 1984. Leaf herbivores decrease fitness of a tropical plant. Science, 226: 537-539.

Nunes, K.A., Cassin, C.M., and Kotanen, P.M. 2016. Variation in herbivory along a latitudinal gradient for native and exotic Asteraceae. Plant Ecol. 217: 481-493.

Salgado-Luarte, C., and Gianoli, E. 2010. Herbivory on temperate rainforest seedling in sun and shade: resistance, tolerance and habitat distribution. PLoS ONE, 5: 1-7.

Schoonhoven, L.M., van Loon, J.J.A., and Dicke, M. 2005. Insect-Plant Biology. Oxford University Press, Oxford, UK.

Straw, N.A. 1991. Resource limitation of tephritid flies on lesser burdock, Arctium minus (Hill) Bernh. (Compositae). Oecologia (Berlin), 86: 492-502.

Torchin, M.E., and Mitchell, C.E. 2004. Parasites, pathogens, and invasions by plants and animals. Front. Ecol. Environ. 2: 183-190.

Van Valen, L. 1973. Pattern and the balance of nature. Evolutionary Theory, 1: 31-49.

Walter, J., Hein, R., Auge, H., Beierkuhnlein, C., Loffler, S., Reifenrath, K., Schadler, M., Weber, M., and Jentsch, A. 2012. How do extreme drought and plant community composition affect host plant metabolites and herbivore performance? Arthropod-Plant Interactions, 6: 15-25.

Woods, E.C., Hastings, A.P., Turley, N.E., Heard, S.B., and Agrawal, A.A. 2012. Adaptive geographical clines in the growth and defense of a native plant. Ecol. Monogr. 82: 149-168. 
Table 1: ANOVA results comparing leaf and seed damage of common burdock at multiple sites and in two habitats (understory and open). Models also included Population as a blocking factor. Significant results $(p<0.05)$ indicated in bold.

\begin{tabular}{|c|c|c|c|c|c|c|c|c|c|}
\hline \multirow[b]{2}{*}{ Source } & \multicolumn{3}{|c|}{ Percent area removed } & \multicolumn{3}{|c|}{ Larvae per capitulum } & \multicolumn{3}{|c|}{$\begin{array}{l}\text { Proportion of seeds } \\
\text { damaged }\end{array}$} \\
\hline & $F$ & $\mathrm{df}$ & $p$ & $F$ & $\mathrm{df}$ & $p$ & $F$ & $\mathrm{df}$ & $p$ \\
\hline Habitat & 7.4776 & 1,40 & 0.0093 & 8.0517 & 1,25 & 0.0089 & 5.1907 & 1,25 & 0.0315 \\
\hline Site & 3.3243 & 4,40 & 0.0193 & 5.4082 & 4,25 & 0.0028 & 2.8846 & 4,25 & 0.0431 \\
\hline Site $\mathrm{x}$ Habitat & 2.1827 & 4,40 & 0.0884 & 0.3691 & 4,25 & 0.8283 & 0.2221 & 4,25 & 0.9235 \\
\hline
\end{tabular}




\section{Figure Captions}

Figure 1: Differences between open and understory habitats in herbivory on common burdock at five different sites. Means are shown \pm standard error; see Table 1 for statistical results. A) The average percent area damage to leaves. Damage was significantly greater in understory than open sites; sites also differed significantly, but there was no habitat x site interaction. B) The average number of $M$. lappella larvae in burdock seedheads. Capitula in understory habitats contained significantly more $M$. lappella than capitula in open habitats; sites also differed significantly. C) The proportion of seeds damaged per capitulum. The fraction damaged was greater in understory sites; sites also differed significantly. 

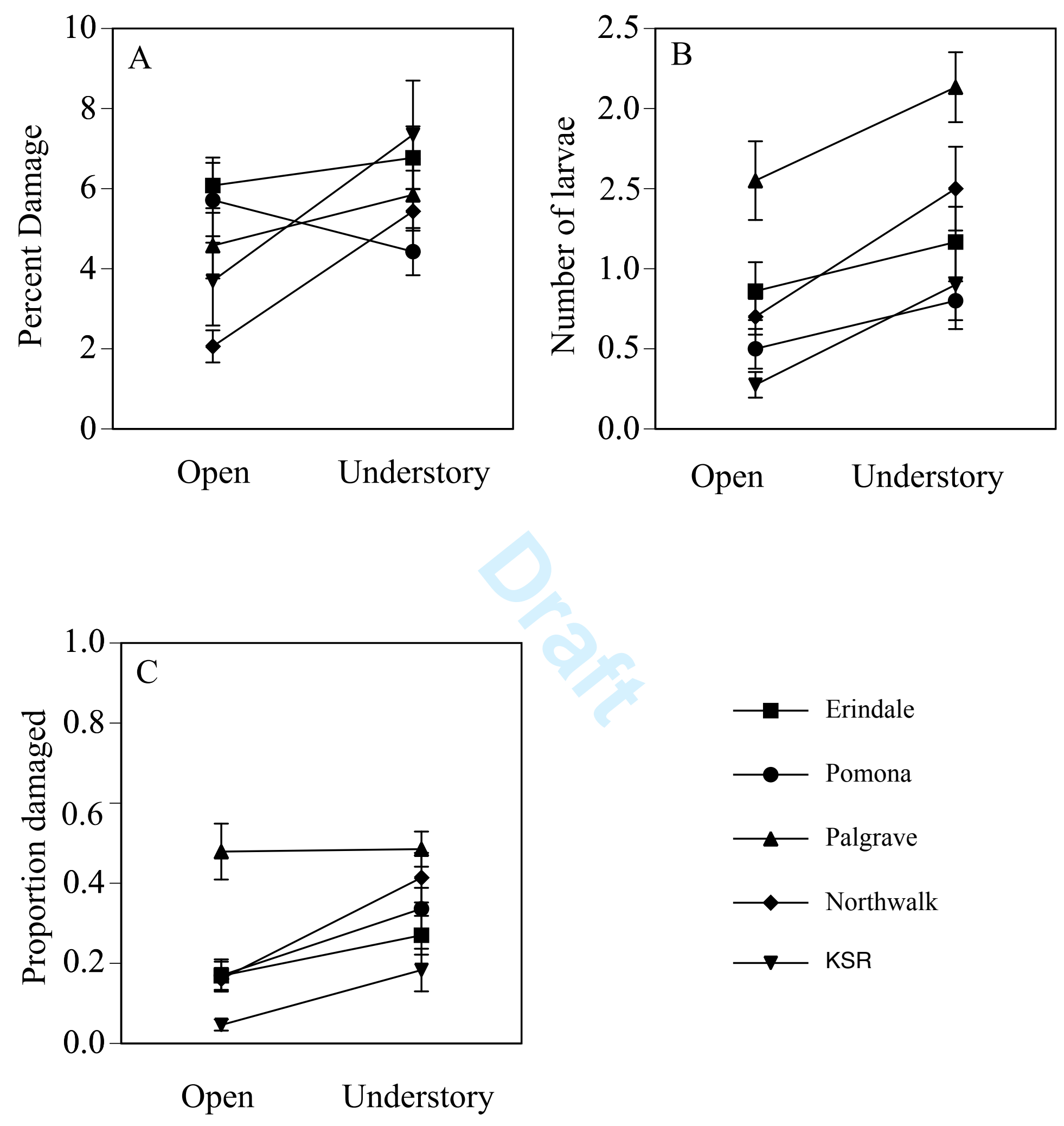